\title{
Textural Properties of Nickel, Palladium and Titanium Oxides Supported on MCM-41 Materials and Their Application on Oxidative Desulfurization of Dibenzothiophene
}

\author{
Regivânia L. M. Franco ${ }^{\mathrm{a}}$, Thiago G. Oliveira ${ }^{\mathrm{b}}$, Anne M. Garrido Pedrosa ${ }^{\mathrm{b}}$, \\ Sandro Naviciene ${ }^{\mathrm{b}}$, Marcelo J. B. Souza ${ }^{\mathrm{c} *}$ \\ ${ }^{a}$ Programa de Pós-graduação em Ciência Engenharia de Materiais - $P^{2} C E M$, \\ Universidade Federal de Sergipe - UFS, Cidade Universitária Professor José Aloísio de Campos, \\ Av. Marechal Rondon, s/n, Jardim Rosa Elze, CEP 49100-000, São Cristóvão, SE, Brasil \\ ${ }^{\mathrm{b}}$ Departamento de Química - DQI, Universidade Federal de Sergipe - UFS, \\ Cidade Universitária Professor José Aloísio de Campos, Av. Marechal Rondon, s/n, \\ Jardim Rosa Elze, CEP 49100-000, São Cristóvão, SE, Brasil \\ ${ }^{\mathrm{c}}$ Departamento de Engenharia Química - DEQ, Universidade Federal de Sergipe - UFS, \\ Cidade Universitária Professor José Aloísio de Campos, Av. Marechal Rondon, s/n, \\ Jardim Rosa Elze, CEP 49100-000, São Cristóvão, SE, Brasil
}

Received: September 25, 2012; Revised: August 31, 2013

\begin{abstract}
Textural and catalytic properties of nickel, palladium or titanium oxides supported on MCM-41 materials were evaluated in this paper. The results indicated that the MCM-41 material with well defined and highly ordered hexagonal structure was obtained. After metal ions impregnation and calcinations, the structure of MCM-41 was preserved and formed metallic oxide particles, however the decreased of surface area of these structures occurred. The catalysts studied showed maximum conversion levels of dibenzothiophene in the range of 50-65\%.
\end{abstract}

Keywords: MCM-41, transition metals oxides, oxidative desulfurization

\section{Introduction}

The search for materials with more appropriated properties has been focus of many studies in the last decades ${ }^{1,2}$. The MCM-41 material is an alternative for various processes because it allows the processing of various sizes molecules, allowing good diffusion of several compounds, thereby improving the effectiveness of reaction at internal surface, combined with properties that make these potential solid supports and catalysts for various industrial applications $\mathrm{s}^{3-5}$.

Mesoporous materials supported with transition metals oxides are an important alternative for the development of catalysts capable of acting on several industrial processes that need reactivity on oxidations and reduction reactions, furthermore, the high surface area and pore diameter of the MCM-41 may lead to attractive for industrial processes $^{5,6}$. However, this support can be catalytically inactivated or present very weak acid sites ${ }^{3,5}$, which will require the introduction of active phases. The d-block oxide dispersion, which present Lewis acid sites, over the support with high superficial area, as MCM-41, maximize the contact area between reactants and active sites, creating favorable conditions for the chemical reactions of sulfurous compounds conversion present in fossil fuels ${ }^{7,8}$. The metallic oxides, as for nickel, palladium and titanium can easily change their valence state, promote the redox cycle and therefore, present good desulfurization outcomes. The active

*e-mail: marcelojbs@ufs.br phases can change the structural and morphologic properties of the final catalysts, capable of enhancing their stability and activity for this process ${ }^{7-10}$.

One of the main applications of the silica mesoporous matrix containing metals is the desulfurization of automotives fuels ${ }^{9}$. With environmental regulations even more rigorous, refineries are facing the inevitable reality that they will need to produce fuels with minimal amounts of sulfur ${ }^{7}$. The conventional hydrotreating has its efficiency limited by the reduction in the sulfur amount when considering constituents with high molar mass, such as dibenzothiophene. Alternative techniques are being developed in the last years, such as oxidative desulfurization, which has been seen as a promising method for sulfur amount reduction on fuels, being used in large scale by petroleum refinery industries ${ }^{2,5}$. The oxidative desulfurization has a mechanism that promotes a polarity change in sulfur compounds, facilitating their separation from other components present in the fuel, and enabling their extraction with polar solvent or adsorbents ${ }^{10}$.

Thus, there is a need to improve existing catalytic processes in refineries with the concept of developing more active and selective catalysts for the process of removing sulfur compounds present in petroleum. In this work the synthesis and characterization of NiO/MCM-41, PdO/MCM-41 and $\mathrm{TiO}_{2} / \mathrm{MCM}-41$ catalysts are shown, a study on the effects of the active phases in structural and morphological characteristics of the final catalysts and 
the results obtained from the catalytic tests of oxidative desulfurization of dibenzothiophene, seeking to contribute in overcoming one of the major and recent industrial challenge existent in the petroleum refinery industry, the significant reduction of sulfur amounts present in fossil fuel.

\section{Experimental}

The MCM-41 material was synthesized using hydrothermal method at $100{ }^{\circ} \mathrm{C}$ during three day and using silica gel 60 (70-230 mesh, Carvalhares), sodium silicate $\left(\mathrm{SiO}_{2}-\mathrm{Na}_{2} \mathrm{O}, \mathrm{Vetec}\right)$, hexadecyltrimethylammonium bromide (CTMABr, Vetec) and distilled water as starting materials and in accordance with the procedure previously described by Souza et al. ${ }^{3}$. The MCM-41 material was prepared with the following molar composition: $4.58 \mathrm{SiO}_{2}$ : $0.437 \mathrm{Na}_{2} \mathrm{O}: 1.00 \mathrm{CTMABr}: 200 \mathrm{H}_{2} \mathrm{O}$. After the hydrothermal synthesis, the material obtained was washed with water, dried and calcinated at $450{ }^{\circ} \mathrm{C}$ for 4 hours in order to remove the template from the pore structure. The MCM-41 material containing oxides of titanium, nickel or palladium, as active phases, were prepared by the impregnation method, starting from titanium chloride, nickel nitrate and palladium chloride as the precursors followed by calcination at $450{ }^{\circ} \mathrm{C}$ for 2 hours under an oxidant atmosphere, with a heating rate of $5{ }^{\circ} \mathrm{C} \mathrm{min}-1$. The catalysts were prepared in order to obtain materials supported on the MCM-41 with $10 \%$ of weight of the respective metals. These is values are in accordance with loadings used in typical desulfurization processes ${ }^{6,7}$

The MCM-41 and oxide metals supported on MCM-41 materials obtained were characterized by nitrogen adsorption, X-ray diffraction (XRD), Fourier-transform infrared spectroscopy (FTIR), elemental analysis and thermogravimetric analysis (TGA). X-ray diffraction measurement was carried out in Rigaku (MiniFlex II) $\mathrm{X}$-ray equipment using $\mathrm{CuK} \alpha$ radiation in $2 \theta$ angle of $1.5^{\circ}$ to $10^{\circ}$ and until $60^{\circ}$ with step of $0.01^{\circ}$. Energy dispersive analyses were carried out on an EDX-720 instrument. the adsorption - desorption isotherms of nitrogen were performed at $77 \mathrm{~K}$ by using a NOVA $1200 \mathrm{e}$ analytical system made by Quantachrome Corporation to determine the physical properties such as pore diameter, pore volume, pore wall thickness and surface area of calcinated materials. The specific surface area (SSA) was calculated using the Brunauer-Emmett-Teller (BET) method for $\mathrm{P} / \mathrm{P}_{0}$ ranged between 0.05 and 0.30 . Pore volumes determined by nitrogen adsorption at a relative pressure of 0.99 and pore size distributions from the branch isotherms adsorption by Barrett-Joyner-Halenda (BJH) method, were also taken into account. Pore wall thicknesses were estimated with the expression: $\mathrm{w}_{\mathrm{t}}=\left[\mathrm{a}_{0}-\mathrm{D}_{\mathrm{p}}\right]^{3,6}$ for MCM-41. A Perkin Elmer Spectrum BX FTIR spectrometer was used to obtain the IR spectra of the samples and evaluate the efficiency of the calcination process. The effective range was from 400 to $4000 \mathrm{~cm}^{-1}$. The thermal properties were carried out in Shimadzu equipment, TGA-50 model, using nitrogen as gas carrier flowing at $40 \mathrm{~mL} \mathrm{~min}{ }^{-1}$. The samples were heated from room temperature up to $900{ }^{\circ} \mathrm{C}$, at a heating rate of $10{ }^{\circ} \mathrm{C} \min ^{-1}$.

The analysis of Transmission Electron Microscopy (TEM) of the samples were performed using a Philips
CM-120 instrument of the LCE/UFSCar, with an electron beam accelerating voltage of $120 \mathrm{kV}$; the sample was dispersed ultrasonically in 2-propanol, and a drop of the suspension was deposited on a holey carbon copper grid.

The catalysts synthesized were tested in the model reaction of oxidative desulfurization using a mixture model composed of $500 \mathrm{ppm}$ of dibenzothiophene (DBT) in $n$-heptane, $\mathrm{H}_{2} \mathrm{O}_{2}$, acetonitrile as solvent extractor and a slurry bed reactor. The catalytic tests were performed at temperatures of $25^{\circ} \mathrm{C}$ and $60^{\circ} \mathrm{C}$, pressure of 1 atm, total reaction time of 60 minutes and $50 \mathrm{mg}$ of catalyst. Aliquots were analyzed in liquid chromatograph from Shimadzu, model DGU-20A3 degasser, UV-Visible detector with a photodiode array model SPD-M20A, two pump systems reciprocantes model LC-20AT.

\section{Results and Discussions}

XRD patterns for MCM-41, NiO/MCM-41, PdO/ MCM-41 and $\mathrm{TiO}_{2} / \mathrm{MCM}-41$ are shown in Figure 1. The support synthesized in the calcinated form and non-calcinated has a higher intensity peak at $2.4^{\circ}$ related to the index (100) and lower intensity, observed in the range $3-7^{\circ}$, corresponding to the lines of reflection planes (110) and (200), characteristic of the hexagonal phase material ordered like MCM-41 ${ }^{[1]}$ (Figure 1a). These results also show that removal of the template via calcination did not affect the structure of the material (Figure 1a).

According to XRD data, no significant changes occurred in the lattice parameters of the MCM-41 hexagonal structure after impregnation of nickel, palladium or titanium ions (Figures $1 \mathrm{~b}$ to $1 \mathrm{~d}$ ). Only a mild deviation in the main reflection angle was seen, which could be attributed to the incorporation of metallic ions ${ }^{5}$, also observed in the MET (Figure 4). This behavior shows that when MCM-41 is impregnated with metallic oxides, its pores can lose or reduce its ordination, however the incorporation ions of these oxides in the mesopores did not affect the amorphous structure of the support walls. This aspect is important for the good outcome of the catalyst. The presence of nickel, palladium or titanium oxides phases along with the MCM-41 materials were observed in the prepared samples. Peaks corresponding to $\mathrm{NiO}$ phase ${ }^{12}$ was confirmed by the low intensity peaks at $2 \theta=37.1^{\circ}$ and $43.2^{\circ}$ (Figure $1 \mathrm{~b}$ ). Also $\mathrm{PdO}$ phase was identified by peaks at $2 \theta=33.6^{\circ}, 41.7^{\circ}$ and $54.4^{\circ}$ (Figure 1c). The titanium oxide showed peaks with $2 \theta=25.5^{\circ}, 38.1^{\circ}, 48.1^{\circ}$ and $54.5^{\circ}$ which are characteristic of anatase titanium IV oxide $^{5}$ (Figure 1d). Similar results were also previously found in other works when the nickel or palladium was supported on siliceous materials ${ }^{12,13}$.

FTIR spectra for MCM-41 calcinated and non-calcinated samples are shown in Figure 2. For non-calcinated samples several bands are evident, related both to deformations and stretching of the functional groups of organic species of the template $\left(\mathrm{CTMA}^{+}\right)$, as well as, inorganic functional groups present in the structure of the MCM- $41^{[11]}$. The calcinated samples showed bands attributed to $\mathrm{Si}-\mathrm{O}$ bond. In all samples the presence of a broad band with a maximum at $3460 \mathrm{~cm}^{-1}$ which is assigned to the silanol groups and hydroxyl groups on internal and external structure was observed. However, only the non-calcinated material has 


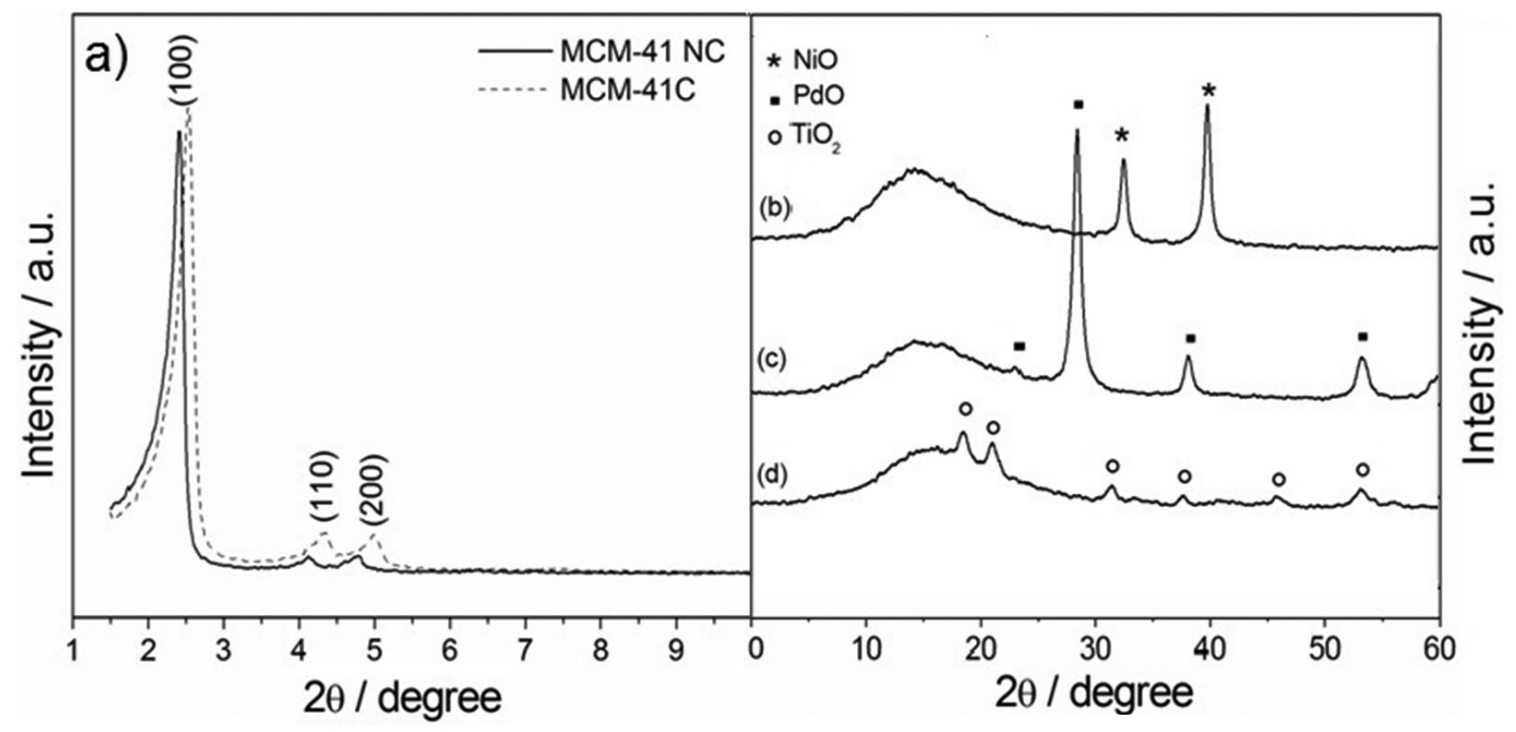

Figure 1. XRD patterns for (a) MCM-41 calcinated (C) and non-calcinated (NC); (b) NiO/MCM-41; (c) PdO/MCM-41 and (d) TiO/ MCM-41.

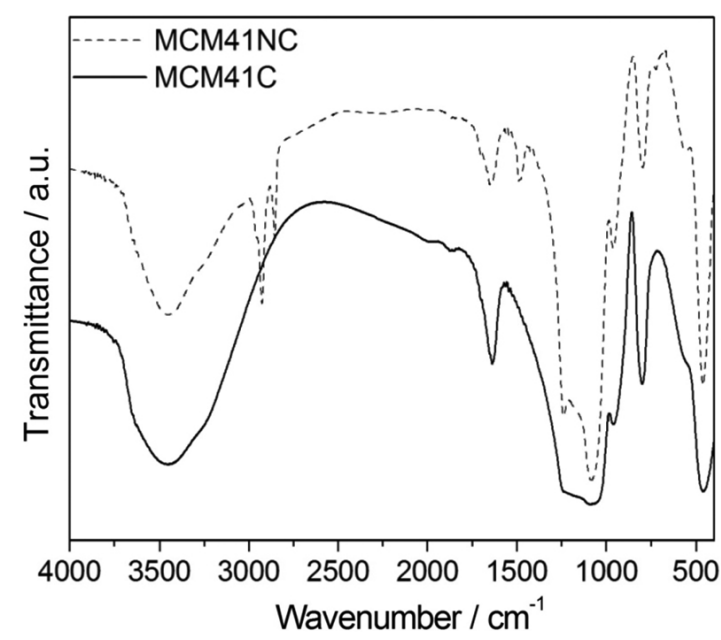

Figure 2. IR spectra for MCM-41 calcinated (C) and non-calcinated (NC).

absorption bands in the region between 2850 to $2990 \mathrm{~cm}^{-1}$, characteristic of the $\mathrm{CH}$ stretching of the $\mathrm{CH}_{2}$ and $\mathrm{CH}_{3}$ groups which are due to the presence of the surfactant molecules on the MCM-41 mesoporous. Non-calcinated samples also present at $1475 \mathrm{~cm}^{-1}$ which is attributed to deformation of the $\mathrm{CTMA}^{+}$ions. These results confirm the efficiency of the calcination process in removing the template from the mesopores. All materials show bands at $1240 \mathrm{~cm}^{-1}$ and $800 \mathrm{~cm}^{-1}$ which are assigned to symmetric and asymmetric stretching of the Si-O-Si bond, which are very common in silicates. Further, the materials shown an absorption band in the range of 1550 to $1750 \mathrm{~cm}^{-1}$ attributed to water interacting with the support surface ${ }^{11}$. The IR spectra of the NiO/MCM-41, PdO/MCM-41 and $\mathrm{TiO}_{2} / \mathrm{MCM}-41$ (Figure not shown) are very similar to that of MCM-41, which indicated that the impregnation treatment of the nickel, palladium or titanium ions on the MCM-41 did not affect the structure of this material. Bands related to $\mathrm{M}-\mathrm{O}$ ( $\mathrm{M}=\mathrm{Ni}, \mathrm{Pd}$ or $\mathrm{Ti}$ ) bond were not observed in the range studied. According to Popova et al..$^{5}$, this can be an indicative that the coordinated metallic ions on the silica matrix induce insignificant alterations in the NiO/MCM-41, $\mathrm{PdO} /$ MCM-41 and $\mathrm{TiO}_{2} / \mathrm{MCM}-41$ spectrum when comparing with the MCM-41 support spectrum, suggesting that there was a low incorporation of metallic oxides in the interior of the silica matrix.

The TG curves for MCM-41 calcinated, MCM-41 non-calcinated, and MCM-41 impregnated with the precursor containing nickel, palladium or titanium was obtained. The thermogravimetric curve for MCM-41 non-calcinated (Figure 3a) showed three regions of mass loss in the temperature range of $30-550{ }^{\circ} \mathrm{C}$, which are related to decomposition of the $\mathrm{CTMA}^{+}$ions present in the pores of MCM-41. At $550{ }^{\circ} \mathrm{C}, 60 \%$ residual of the original mass is composed of MCM-41. The TG curve of the calcinated MCM-41 (Figure 3a) showed mass loss in the range $30-600{ }^{\circ} \mathrm{C}$, which is due to both the desorption of adsorbed water molecules, as well as, the loss of silanol groups existing on the calcinated material ${ }^{11-14}$.

Samples of MCM-41 impregnated with precursors of nickel (Figure 3b), palladium (Figure 3c) or titanium (Figure 3d) presented respective mass loss in the temperature range of 30 to $900{ }^{\circ} \mathrm{C}$, data shown in detail in Table 1 . This mass loss observed in all samples are related to decomposition of water molecules present in the prepared catalysts, as well as, the decomposition of the MCM-41 impregnated with precursor salts. The thermogravimetric analysis shows that the materials acquire stable composition at about $450{ }^{\circ} \mathrm{C}$ because after this temperature is no mass loss is observed. These results indicate that in this temperature the precursor salts were completely decomposed, resulting in 


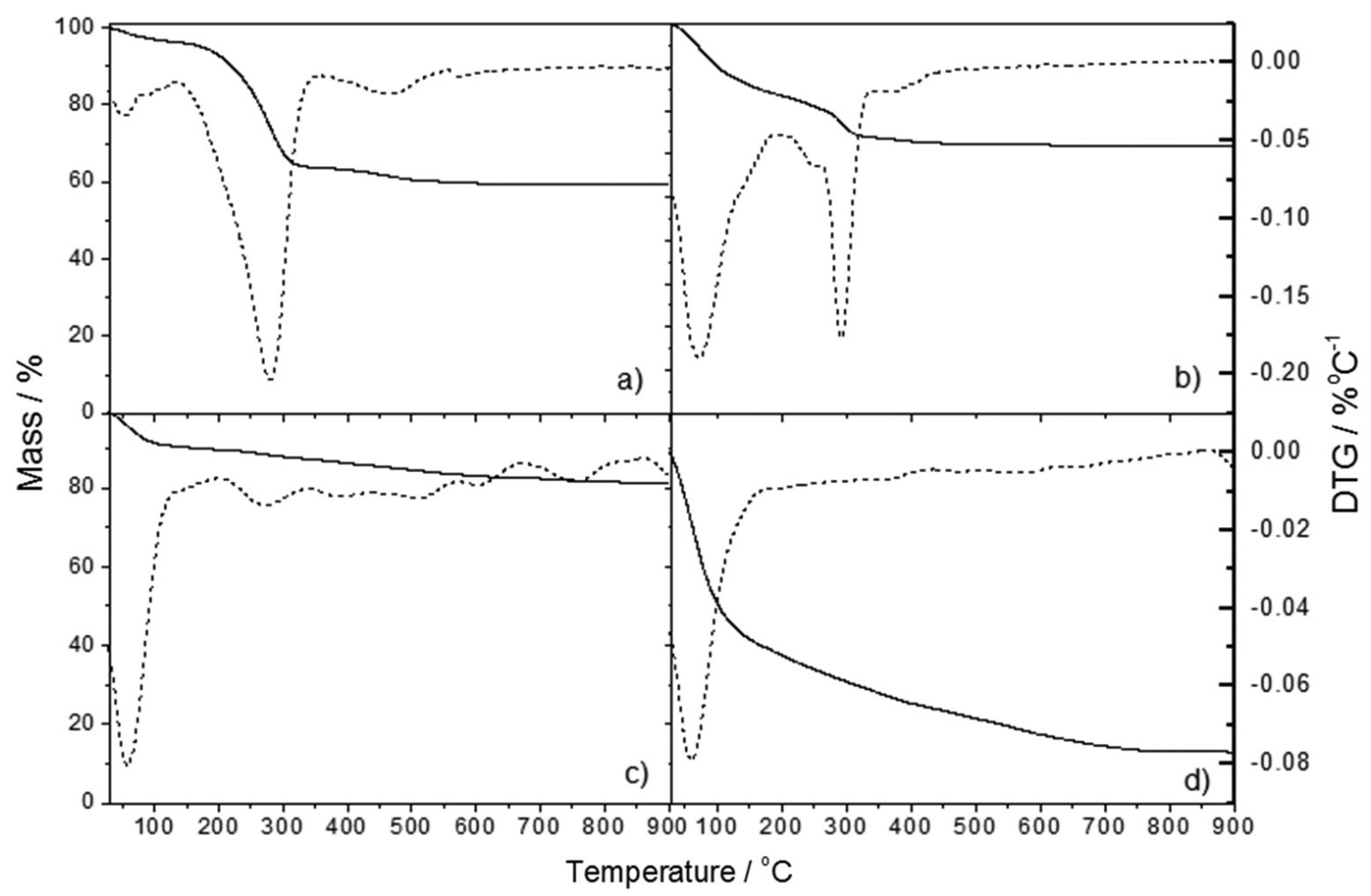

Figure 3. TG curves for (a) MCM-41 calcinated (C) and non-calcinated (NC); (b) NiO/MCM-41; (c) PdO/MCM-41 and (d) TiO $/ 2$ MCM-41.

Table 1. Mass loss $(\%)$ and temperature range $\left({ }^{\circ} \mathrm{C}\right)$ for decomposition of MCM-41 and MCM-41 modified materials precursors. $\mathrm{NC}=$ non-calcinated and $\mathrm{C}=$ calcinated.

\begin{tabular}{lcccc}
\hline \multirow{2}{*}{ Sample } & \multicolumn{4}{c}{ Temperature range $\left({ }^{\circ} \mathbf{C}\right) /$ mass loss } \\
\cline { 2 - 5 } & $\mathbf{3 0 - 1 0 0}$ & $\mathbf{1 0 0 - 3 5 0}$ & $\mathbf{3 5 0 - 4 5 0}$ & $\mathbf{3 0 - 4 5 0}$ \\
\hline MCM-41 NC & 6.0 & 39.0 & 2.0 & 47.0 \\
MCM-41 C & 3.75 & 1.84 & 1.5 & 7.09 \\
\hline & $\mathbf{3 0 - 1 5 0}$ & $\mathbf{1 5 0 - 3 0 0}$ & $\mathbf{3 0 0 - 4 5 0}$ & $\mathbf{3 0 - 4 5 0}$ \\
\hline $\mathrm{NiO} / \mathrm{MCM}-41$ & 15.8 & 13.4 & 1.6 & 30.80 \\
$\mathrm{PdO} / \mathrm{MCM}-41$ & 8.64 & 3.51 & 2.32 & 14.47 \\
$\mathrm{TiO}_{2} / \mathrm{MCM}-41$ & 11.90 & 4.71 & 2.25 & 18.86 \\
\hline
\end{tabular}

the formation of the metal oxides on the support. However, the thermogravimetric analysis was very efficient when monitoring the synthesis and formation of MCM-41, as well as estimating the final material quality. The thermograms (Figure 3) indicate that the samples present high thermal stability, supported by other authors ${ }^{11,14}$, as well as relevant properties for the catalyst field.

The textural properties results of the prepared catalysts are shown in Table 2. The nitrogen adsorption analysis of the MCM-41 support and using the BET method, confirmed the achievement of a mesoporous material having a specific surface area of about $800 \mathrm{~m}^{2} \mathrm{~g}^{-1}$. The average pore diameter obtained by the BJH method was $3.60 \mathrm{~nm}$ and the volume of the mesoporous was $0.50 \mathrm{~cm}^{3} \mathrm{~g}^{-1}$. In addition to these properties, we calculated the wall thickness of the MCM-41 silica based on the data of $\mathrm{XRD}$ and $\mathrm{BJH}^{15}$ whose value corresponds to $2.6 \mathrm{~nm}$. These results demonstrate that catalysts with textural characteristics relevant to the field of catalysis $^{3,6}$, considering the high values of specific surface area, pore volume and pore diameter were developed, also compatible with the data obtained ${ }^{15}$.

The impregnation of nickel, palladium or titanium ions in the MCM-41 led to a reduction in area and pore volume of catalyst synthesized according to the increase in metal content impregnated, this was probably because of the filling of the MCM-41 pores by the respective metal oxides. The material presents open pores, connected directly to the MCM-41 surface, with access to ions hosts, such as metallic oxides. Data indicate that there was no significant blockage of the pores by oxide particles of nickel, palladium and titanium incorporated to the MCM-41 mesopore structure. However, there was a reduction of the mesopores volumes which can be caused by oxide charges, resulting in the 
hexagonal structure contraction ${ }^{5,9}$, compatible with the XRD results.

Figure 4 shows TEM images of the synthesized samples MCM-41, NiO/MCM-41, PdO/MCM-41 and $\mathrm{TiO} / \mathrm{MCM}-41$, respectively. The morphology of MCM-41 (Figure 4a) has a regular unidimensional pore system with uniform array of mesoporous channels highly ordered long-range structure, which can also be confirmed by the XRD patterns (see Figure 1) in accordance with the literature $^{15-18}$. The pore size observed from TEM image is consistent with that determined by $\mathrm{N}_{2}$ adsorption (see Table 2).

TEM images (Figures $4 \mathrm{~b}$ to $4 \mathrm{~d}$ ) show that most of the $\mathrm{NiO}, \mathrm{PdO}$, and $\mathrm{TiO}_{2}$ of the prepared catalyst are small particles and were well distributed inside the pores of the MCM-41, which also was observed in other studies ${ }^{19-21}$.
TEM analysis shows the microstructure of the catalysts obtained with oxides of nickel, palladium or titanium (dark spots) on the surface of the MCM-41.

It is noteworthy that even with the incorporation of $\mathrm{NiO}$, $\mathrm{PdO}$ or $\mathrm{TiO}_{2}$ particles, the MCM-41 still maintains a good structural order in all samples analyzed. Previous work ${ }^{20,21}$ also showed that the formation of particles did not affect the structure of highly ordered mesoporous host materials consistent with the results of XRD (see Figure 1).

The selection of the catalysts support is considered important in the desulfurization process, since it may influence both the reaction activity and selectivity. Recent studies have indicated that the transition metals oxides are promising materials for these processes ${ }^{22-27}$. However, the use of these materials is limited because the specific surface area, volume and pore diameter are low. Moreover, the

Table 2. Textural properties and chemical composition of MCM-41, NiO/MCM-41, PdO/MCM-41 and TiO $/$ MCM-41 samples, where: $\mathrm{SSA}=$ specific surface area; $\mathrm{Vp}=$ pore volume; $\mathrm{Dp}=$ pore diameter; $\mathrm{M}(\%)=\mathrm{Ni}, \mathrm{Pd}$ or $\mathrm{Ti}(\%)$.

\begin{tabular}{lcccc}
\hline \multicolumn{1}{c}{ Sample } & $\mathbf{S S A}\left(\mathbf{m}^{2} \mathbf{g}^{-1}\right)$ & $\mathbf{V p ~}\left(\mathbf{c m}^{3} \mathbf{g}^{-1}\right)$ & Dp $(\mathbf{n m})$ & M (\%) \\
\hline MCM-41 & 805 & 0.48 & 3.651 & - \\
NiO/MCM-41 & 364 & 0.28 & 3.605 & 10.18 \\
PdO/MCM-41 & 547 & 0.39 & 3.621 & 10.97 \\
$\mathrm{TiO}_{2} /$ MCM-41 & 428 & 0.35 & 3.610 & 10.87 \\
\hline
\end{tabular}

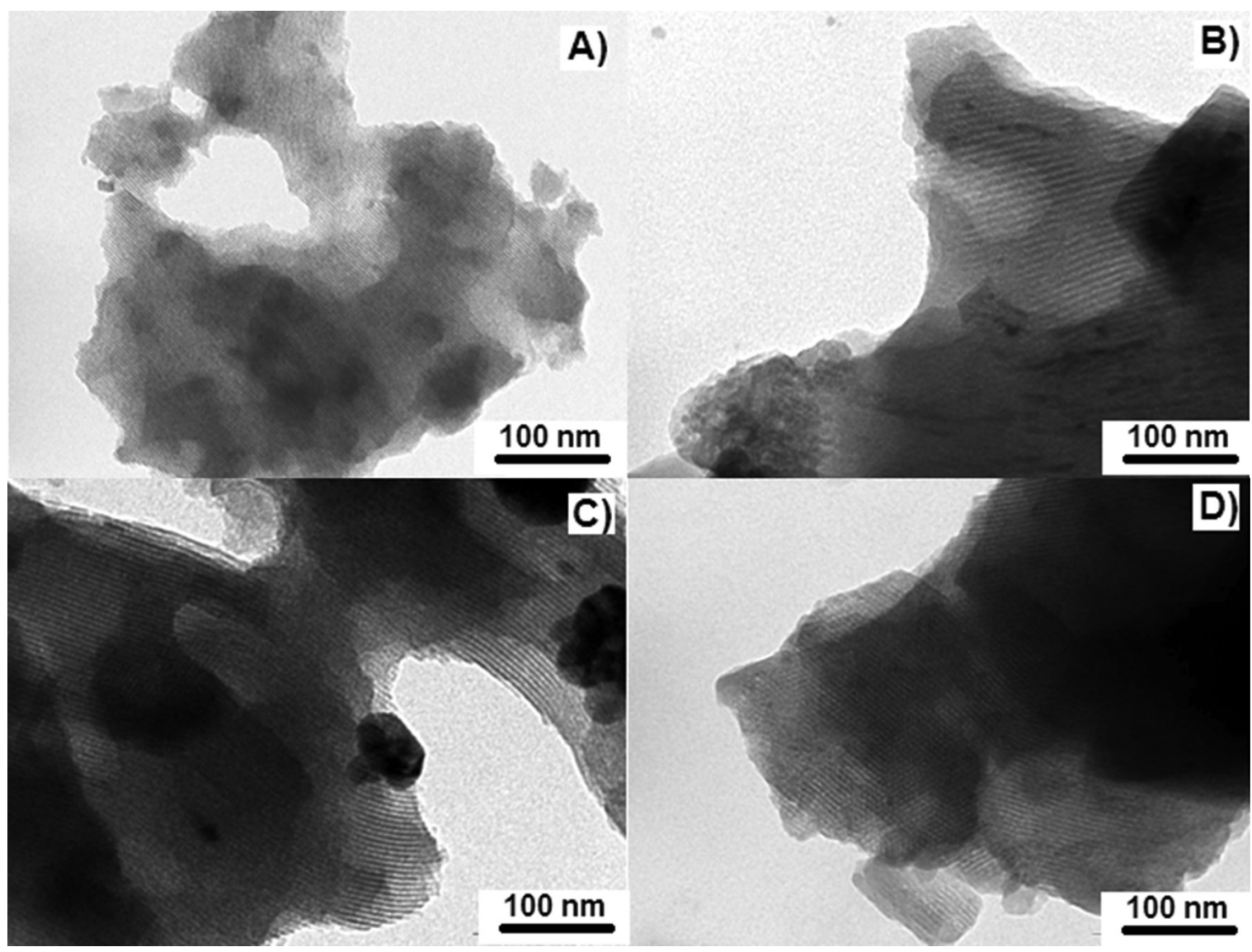

Figure 4. TEM images of mesoporous materials: (a) MCM-41, (b) NiO/MCM-41, (c) PdO/MCM-41 and (d) $\mathrm{TiO}_{2} / \mathrm{MCM}^{-41}$. 
formation of organic sulfides on the surface for adsorption processes would result in blocking of acid sites in the pores, and hence, decrease in capacity to remove sulfur compounds $^{22}$. Therefore, mesoporous materials of high surface area have been synthesized for use as catalyst support in order to address the shortcomings of d-block transition metals oxides ${ }^{24-26}$ used for this purpose. The use of supported catalysts containing porous support with an appropriate textural property and containing an active phase based on oxides of the d-block transition metal has been developed. Figure 5 shows catalytic activities on the oxidative desulfurization reaction at 25 and $60{ }^{\circ} \mathrm{C}$ of the synthesized material.

The conversion of dibenzothiophene increases significantly in the first few minutes of reaction and remains constant until 60 minutes later. The best performance was displayed by the catalyst $\mathrm{TiO}_{2} / \mathrm{MCM}-41$ showing a maximum conversion of $65 \%$. The better performance of $\mathrm{TiO}_{2} / \mathrm{MCM}-41$ is associated with the presence of $\mathrm{Ti}^{4+}$ species well dispersed in the silica matrix which may increase the activity of the oxidation catalyst. Furthermore, this catalyst is less subject to deactivation that can occur due to leaching of heavy metals and adsorption of highly polar sulphones on the catalyst surface ${ }^{22}$. The activity of the NiO/MCM-41 is due to direct interaction between the sulfur and the surface of nickel ions. The results also show that the increasing in temperature caused an increase in the conversion.

Typically, the catalytically active component must be applied as a thin layer on the surface of the support and distribution in the catalyst depends on the conditions under which the catalyst is applied. The results presented here showed that particles of nickel, palladium or titanium oxides uniformly distributed/dispersed in the mesoporous MCM-41, and are biased so as not to cause considerably blockage of the support pores.

Although the MCM-41 pore size is big, at the adsorption onset a great amount of DBT molecules have rapid accessibility to the nickel, palladium and titanium particles and are converted. However, the speed in which this occurs may have provoked a blockage of catalyst pores, where the conversion reaches a maximum value and is then stable, see Figure 5. Previous work ${ }^{7,13,27}$ showed that this inconvenient may be reduced with an enhanced control of the metallic oxide particle size, thus, the smaller they are, higher is the amount of active sites, lower is the steric impeachment during the metallic oxide nanoparticles interaction with sulfur atoms and, consequently, higher is the adsorption capacity.

The interaction of molecules containing sulfur heteroatoms in the supported catalysts based on oxides of titanium, nickel or palladium is expected to not occur in the same manner, considering that titanium is a hard acid ${ }^{24}$, whereas nickel and palladium are soft acids and this effect can strongly adsorb organic molecules with thiol or sulfide groups (soft bases).

The palladium-based catalysts and especially titanium synthesized in this work can act as good electronic promoters during formation of the active phase $\mathrm{e}^{27}$ which has the textural properties and morphology of the appropriate active phases, as shown in the analysis of characterization. Therefore, it has proved to be effective desulfurization ${ }^{25}$ agents, which will be tested in the sulfur removal process present in petroleum distillates.

However, recent studies ${ }^{22,23}$ of the different media used in this study, show the effectiveness of nickel oxide in the desulfurization by the number of adsorption of active sites, and also the decrease of an obstacle during the interaction with the particles of nickel atoms and sulfur present in the molecules saturated aromatic compounds, and presented a low cost.

Transition metallic oxides of the d-block are promising materials for the oxidative desulfurization process, however, their use is limited because of the specific superficial area, volume and small pore diameters ${ }^{23,24}$. The MCM-41 use as support for the nickel, palladium and titanium oxides enhanced the structural and textural properties of the oxides,

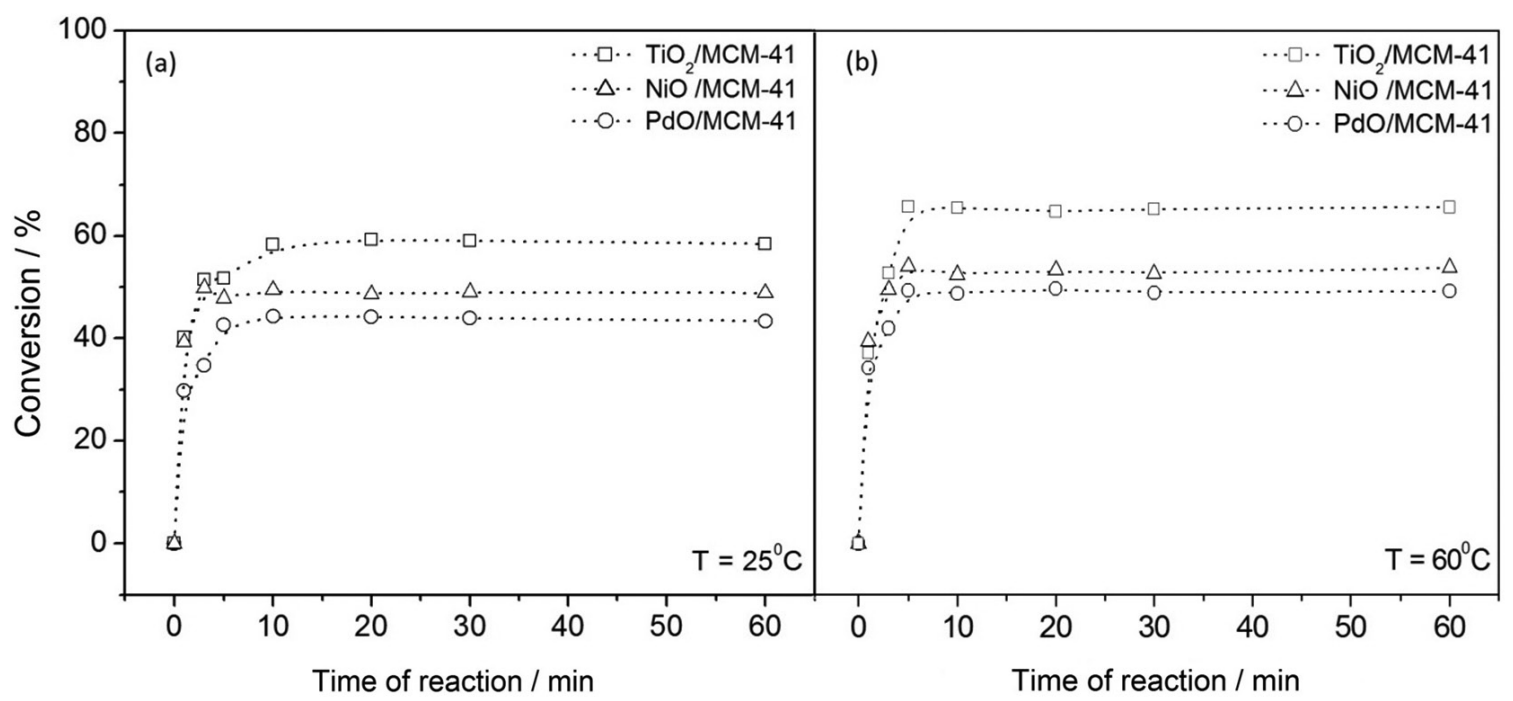

Figure 5. Catalytic test for the oxidative desulfurization reaction at (a) $25{ }^{\circ} \mathrm{C}$ and (b) $60{ }^{\circ} \mathrm{C}$ of the NiO/MCM- 41 , PdO/MCM- 41 and $\mathrm{TiO}_{2} / \mathrm{MCM}-41$. 
promoting an increase in the contact area between the reactants (dibenzothiophene, hydrogen peroxide, molecular oxygen) and active phases (nickel, palladium and titanium oxides), responsible for the higher conversion of DBT.

\section{Conclusions}

The results of the structural characterization of the prepared catalysts showed the formation of the support, with hexagonal structure well defined and highly ordered. For the supported materials the presence of crystalline phases characteristics of the nickel oxide $(\mathrm{NiO})$, palladium $(\mathrm{PdO})$ and titanium $\left(\mathrm{TiO}_{2}\right)$ was also observed. The structural characteristics of the support were maintained after the impregnation of nickel, palladium or titanium ions followed by calcination. Among the three metals studied, titanium was the most affected supporting structure, since nickel caused less influence on the support structure. Nitrogen adsorption shows that the support prepared presented average pore diameter referring to a mesoporous structure, and because of this characteristic, has high potential for adsorption, since porous structure gives them high surface area and potential affinity with bulky organic species. Moreover, while the

\section{References}

1. Speight JG. Handbook of Petroleum analysis. John Wiley \& Sons; 2002.

2. Stanislaus A, Marafi A and Rana MS. Recent advances in the science and technology of ultra low sulfur diesel (ULSD) production. Catalysis Today. 2010; 153:1-68. http://dx.doi. org/10.1016/j.cattod.2010.05.011

3. Souza MJB, Marinkovic BA, Garrido Pedrosa AM, Jardim $\mathrm{PM}$ and Araujo AS. HDS of thiophene over CoMo/ AlMCM-41 with different Si/Al ratios. Applied Catalysis A: General. 2007; 316:212-218. http://dx.doi.org/10.1016/j. apcata.2006.09.030

4. Kwong CW, Chao CYH, Hui KS and Wan MP. Removal of VOCs from indoor environment by ozonation over different porous materials. Atmospheric Environment. 2008; 42:2300-2311. http://dx.doi.org/10.1016/j.atmosenv.2007.12.030

5. Popova M, Szegedi A, Cherkezova-Zheleva Z, Mitov I, Kostova $\mathrm{N}$ and Tsoncheva $\mathrm{T}$. Toluene oxidation on titaniumand iron-modified MCM-41 materials. Journal of Hazardous Materials. 2009; 168:226-232. PMid:19269739. http://dx.doi. org/10.1016/j.jhazmat.2009.02.018

6. Souza MJB, Araujo AS, Aquino JMFB, Garrido Pedrosa AM, Melo DMA et al. Hydrodesulfurization of thiophene over cobalt and molybdenum sulfides supported on MCM-41 materials. Studies in Surface Science and Catalysis. 2005; 156:755-760. http://dx.doi.org/10.1016/S0167-2991(05)80283-6

7. Bakar WAWA, Ali R, Kadir AAA and Mokhtar WNAW. Effect of transition metal oxides catalysts on oxidative desulfurization of model diesel. Fuel Processing Technology. 2012; 101:78-84. http://dx.doi.org/10.1016/j.fuproc.2012.04.004

8. Zhao DS, Sun Z, Shan F and Li H. Optimization of oxidative desulfurization of dibenzothiophene using acidic ionic liquid as catalytic solvent. Journal of Fuel Chemistry and Technology. 2009; 37:194-198. http://dx.doi.org/10.1016/ S1872-5813(09)60015-3

9. Prasad VVDN, Jeong KE, Chae HJ, Kim C and Jeong S. Oxidative desulfurization of 4, 6-dimethyl dibenzothiophene impregnation of the MCM-41 with nickel ions resulted in a smaller loss of structural characteristics, when was compared with other supported catalysts, this action results in a greater loss of surface area of the final catalyst containing nickel as compared with other supported catalysts. The insertion of palladium on the support resulted in a smaller decrease in specific surface area compared to other supported catalysts. This fact is directly related to the particle size on the surface and within the porous support. TEM images agree with the results of XRD and $\mathrm{N}_{2}$ adsorption as regards to the formation of the hexagonal structure, and maintenance of this structure well ordered after impregnation and calcination steps. However, these properties are relevant for application on oxidative desulfurization of dibenzothiophene, as shown in this study.

\section{Acknowledgments}

The authors acknowledge to $\mathrm{P}^{2} \mathrm{CEM}, \mathrm{CAPES}, \mathrm{CNPq}$ (Proc. 475576/2010-1), Instituto Federal de Sergipe (IFS-SE) for financial support and LCE/UFSCar by the Transmission Electron Microscopy (TEM) analysis.

and light cycle oil over supported molybdenum oxide catalysts. Catalysis Communication. 2008; 9:1966-1969. http://dx.doi. org/10.1016/j.catcom.2008.03.021

10. Mei H, Mei BW and Yen TF. A new method for obtaining ultra-low sulfur diesel fuel via ultrasound assisted oxidative desulfurization. Fuel. 2003; 82:405-414. http://dx.doi. org/10.1016/S0016-2361(02)00318-6

11. Souza MJB, Silva AOS, Aquino JMFB, Fernandes VJ Jr and Araujo AS. Kinetic study of template removal of MCM-41 nanostructured material. Journal of Thermal Analysis and Calorimetry. 2004; 75:693-698. http://dx.doi.org/10.1023/ B:JTAN.0000027164.04415.7a

12. Silva AS, Silva FLH, Carvalho MWNC, Pereira KRO and Lima EE. Hidrólise de celulose por catalisadores mesoestruturados NiO-MCM-41 e $\mathrm{MoO}_{3}-\mathrm{MCM}-41$ Química Nova. 2012; 35:683-688.

13. Oemar U, Hidajat $\mathrm{K}$ and Kawi S. Role of catalyst support over PdO-NiO catalysts on catalyst activity and stability for oxy- $\mathrm{CO}_{2}$ reforming of methane. Applied Catalysis A: General. 2011; 402:176-187. http://dx.doi.org/10.1016/j. apcata.2011.06.002

14. Araujo AS and Jaroniec M. Thermogravimetric monitoring of the MCM-41 synthesis. Thermochimica Acta. 2000;175:363-366.

15. Souza MJB, Araujo AS, Pedrosa AMG, Marinkovic BA, Jardim PM and Morgado EJ. Textural Features of Highly Ordered Al-MCM-41 Molecular Sieve Studied By X-Ray Diffraction, Nitrogen Adsorption and Transmission Electron Microscopy. Materials Letters. 2006; 60:2682-2685. http:/ dx.doi.org/10.1016/j.matlet.2006.01.066

16. Wu X, Hui KN, Hui KS, Lee SK, Zhou W, Chen R et al. Adsorption of basic yellow 87 from aqueous solution onto two different mesoporous adsorbents. Chemical Engineering Journal. 2012; 180:91-98. http://dx.doi.org/10.1016/j. cej.2011.11.009

17. Jin S, Cui K, Guan H, Yang M, Liu L and Lan C. Preparation of mesoporous MCM-41 from natural sepiolite and its catalytic activity of cracking waste polystyrene. Applied 
Clay Science. 2012; 56:1-6. http://dx.doi.org/10.1016/j. clay.2011.11.012

18. Liu X, Sun H and Yang Y. Rapid synthesis of highly ordered Si-MCM-41. Journal of Colloid and Interface Science. 2008; 319:377-380. PMid:18067906. http://dx.doi. org/10.1016/j.jcis.2007.11.025

19. Wu C, Wang L, Williams PT, Shi J and Huang J. Hydrogen production from biomass gasification with Ni/MCM-41 catalysts: Influence of $\mathrm{Ni}$ content. Applied Catalysis B: Environmental. 2011; 108-109:6-13. http://dx.doi. org/10.1016/j.apcatb.2011.07.023

20. Tiengchad N, Mekasuwandumrong O, Na-Chiangmai C, Weerachawanasak $\mathrm{P}$ and Panpranot J. Geometrical confinement effect in the liquid-phase semihydrogenation of phenylacetylene over mesostructured silica supported Pd catalysts. Catalysis Communications. 2011; 12:910-916. http:// dx.doi.org/10.1016/j.catcom.2011.01.029

21. Sadjadi MS, Farhadyar N and Zare K. Improvement of the alkaline protease properties via immobilization on the $\mathrm{TiO}_{2}$ nanoparticles supported by mesoporous MCM-41. Superlattices and Microstructures. 2009; 46:77-83. http:// dx.doi.org/10.1016/j.spmi.2008.10.022

22. Guo J, Liang J, Chu Y, Sun M, Yin H and Li J. Desulfurization activity of nickel supported on acid-treated activated carbons. Applied Catalysis A: General. 2012; 421-422:142-147. http:// dx.doi.org/10.1016/j.apcata.2012.02.010

23. Zhang Y, Yang Y, Han H, Yang M, Wang L, Zhang Y et al. Ultra-deep desulfurization via reactive adsorption on $\mathrm{Ni} / \mathrm{ZnO}$ :
The effect of $\mathrm{ZnO}$ particle size on the adsorption performance. Applied Catalysis B: Environmental. 2012; 119-120:13-19. http://dx.doi.org/10.1016/j.apcatb.2012.02.004

24. Subhan F and Liu BS. Acidic sites and deep desulfurization performance of nickel supported mesoporous AlMCM-41 sorbents. Chemical Engineering Journal. 2011; 178:69-77. http://dx.doi.org/10.1016/j.cej.2011.10.013

25. Liu BS, Wan ZY, Zhan YP and Au CT. Desulfurization of hot coal gas over high-surface-area LaMeOx/MCM-41 sorbents. Fuel. 2012; 98:95-102. http://dx.doi.org/10.1016/j. fuel.2012.03.048

26. Samadi-Maybodi A, Teymouri M, Vahid A and Miranbeigi A. In situ incorporation of nickel nanoparticles into the mesopores of MCM-41 by manipulation of solvent-solute interaction and its activity toward adsorptive desulfurization of gas oil. Journal of Hazardous Materials. 2011;192:1667-1674. PMid:21820806. http://dx.doi.org/10.1016/j.jhazmat.2011.06.089

27. Song H, Dai M, Guo Y and Zhang Y. Preparation of composite $\mathrm{TiO}_{2}-\mathrm{Al}_{2} \mathrm{O}_{3}$ supported nickel phosphide hydrotreating catalysts and catalytic activity for hydrodesulfurization of dibenzothiophene. Fuel Processing Technology. 2012; 96:228-236. http://dx.doi.org/10.1016/j. fuproc.2012.01.001 